\title{
Control of PMSG-based Wind Turbines for System Inertial Response and Power Oscillation Damping
}

\author{
Yi Wang, Member, IEEE, Jianhui Meng, Xiangyu Zhang, and Lie Xu, Senior Member, IEEE
}

\begin{abstract}
This paper investigates an improved active power control method for variable speed wind turbines to enhance the inertial response and damping capability during transient events. The optimized power point tracking controller which shifts the turbine operating point from the maximum power point tracking curve to the virtual inertia control curves according to the frequency deviation is proposed to release the "hidden" kinetic energy and provide dynamic frequency support to the grid. The effects of the virtual inertia control on power oscillation damping capability are theoretically evaluated. Compared to the conventional derivative regulator based inertia control, the proposed control scheme can not only provide fast inertial response, but also increase the system damping capability during transient events. Thus, inertial response and power oscillation damping function can be obtained in a single controller by the proposed optimized power point tracking control. A prototype three-machine system containing two synchronous generators and a PMSG based wind turbine with 31 percent of wind penetration is tested to validate the proposed control strategy on providing rapid inertial response and enhanced system damping.
\end{abstract}

Index Terms-Frequency support, permanent magnet synchronous generator, power oscillation damping, variable speed wind turbine, virtual inertia control.

\section{INTRODUCTION}

T $\mathrm{N}$ recent years, the reduced inertial response and power $1_{\text {damping capability as the result of increased wind power }}$ penetration in $\mathrm{AC}$ networks have been receiving considerable attentions from wind turbine manufactures and system operators [1-3]. Tackling these issues requires not only fault ride through capability of the wind turbines, but also the ability to participate in frequency and power regulation during system disturbances, so as to make the wind farms grid friendly power generation sources. Thus, the control potential of variable speed wind turbines need be further explored to ensure the stability of power networks containing large scale wind energy.

Traditional synchronous generators naturally contribute to inertial response with their inherent inertia during frequency events. However, variable speed wind turbines do not directly

This work was supported by the National Natural Science Foundation of China (NSFC) under Grants 51277072 and 50977028

Y. Wang, J. Meng and X. Zhang are with the State Key Laboratory of Alternate Electrical Power System with Renewable Energy Sources, North China Electric Power University, Baoding 071003, China (e-mail: yi.wang@ncepu.edu.cn; mengjianhui2008@163.com).

L. Xu is with the Dept. of Electronic \& Electrical Engineering, University of Strathclyde, Glasgow, UK. contribute to system inertia due to the decoupled control between the mechanical and electrical systems thus preventing the generators from responding to system frequency changes [4-6]. In addition, the Power System Stabilizer (PSS) is normally equipped in the traditional synchronous generators to provide power damping during and after large disturbances. With increased wind penetration, it also becomes essential for wind turbines to provide power oscillation damping [7-8]. This can be critical for weak power systems containing large scale wind farms as damping from synchronous generators may be insufficient and active contribution from wind farms becomes essential.

At present, auxiliary controllers with frequency feedback are introduced to wind turbines to provide system frequency response, such as $\mathrm{P} / f$ droop controller, $\mathrm{PD}$ controller and de-loading controller by shifting the maximum power point tracking (MPPT) curves, etc. [9-16]. However, the $\mathrm{P} / f$ droop controller equipped in the blade pitch control system can only emulate the primary frequency response [9-10]. While the PD controller of the converter employs a $\mathrm{d} f / \mathrm{dt}$ term to emulate additional inertia in the initial frequency change period [3, 11-14], and In [15-16], the power tracking curve is shifted from the MPPT curve to the right sub-optimal curve to provide dynamic frequency support for the grid during a frequency event. However, a smooth recovery to the MPPT operation cannot be realized by these control approaches. Moreover, the damping capabilities of these controllers during grid disturbance are not analysed. The traditional PSS has been introduced to the DFIG to damp power system oscillations but no frequency support was considered [8, 17-20]. For all the work reported, simultaneous inertia and damping control cannot be achieved.

The purpose of this study is to investigate new system control to simultaneously provide inertia response and positive damping during frequency and oscillation events. Smooth recovery of wind turbine operation after inertia response can also be achieved. Due to the increase popularity of PMSG-based wind turbine for applications in large wind farms [21-24], in this paper the proposed integrated control scheme is performed on the PMSG based wind turbine.

This paper is organized as follows. The basic control of the PMSG is briefly introduced firstly. The concept of the virtual inertia of PMSG based variable speed wind turbine is presented, and the design of the virtual inertia controller for dynamic frequency support is described. The damping capability of the proposed virtual inertia controller is analyzed to ensure positive damping coefficient. Experimental studies based on a laboratory power network containing two synchronous 
generators and a PMSG based wind turbine are presented to demonstrate the effectiveness of the proposed schemes on providing inertia response and oscillation damping.

\section{CONTROL OF PMSG}

The proposed inertia and damping control methods are developed considering the power regulation of PMSG-based wind turbine. The dynamic model of the PMSG and associated converters can be found in [25].

The electromagnetic power of the generator can be controlled using either the generator side converter or the grid side converter. In this paper, the grid side converter directly controls the generated active power whereas the generator side converter is used to maintain a constant DC link voltage, as seen in Fig. 1. Since the grid side converter can fall into current limit during $\mathrm{AC}$ voltage dip with reduced power transmission, the generator side converter as the DC voltage control station automatically reduces power generation in order to maintain a constant DC voltage. This control scheme provides automatic power balance during $\mathrm{AC}$ fault and simplifies fault ride through control of the PMSG. The surplus power in the turbine during such disturbances is stored as the kinetic energy of the large rotating masses but only results in a relatively small speed fluctuation of the PMSG. If required, the acceleration of the generator speed can be limited using the pitch control to prevent it from going above its rated value.

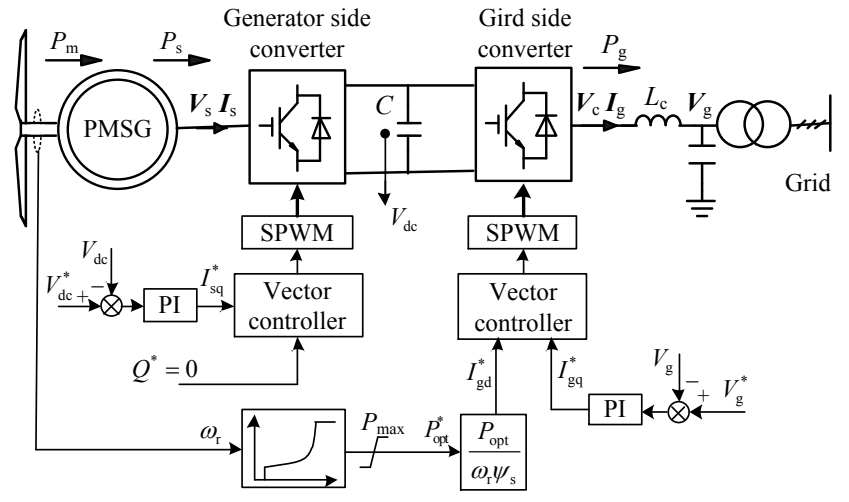

Fig. 1 Schematic control diagram of a PMSG-based wind turbine

Under normal operation, the generated power of the wind turbine is controlled under the MPPT according to its rotor speed, and is independent of the grid frequency due to the fast converter control. The reactive power of the PMSG can be controlled to zero or be regulated to maintain the stator voltage or minimize the power loss of the generator [21]. Therefore, the wind turbine does not naturally response to frequency change or provide power system oscillation damping. In order to emulate the dynamic response of synchronous generators using PMSG based wind turbines, advanced control schemes considering grid frequency deviation need be added to the grid side converter's power control loops. Thus, the rotor speed of the PMSGs is regulated to release/store the kinetic energy to make the "hidden inertia" available to the connected grid, and its flexible power control can also be utilized to participate in power system oscillation damping.

It needs to be noted that the ability for a wind turbine to provide inertia support and damping is based on the condition that the wind turbine and associated generator and converter system have the spare power capability. This means that prior to the network disturbance the wind turbine is operating at below rated power which is usually the case as wind turbines are usually only partially loaded.

\section{VIRTUAL INERTIA CONTROL OF VARIABLE-SPEED WIND TURBINES}

\section{A. Principle of virtual inertia control (VIC)}

The inertia constant $H_{\text {tot }}$ of a power system with synchronous generators and variable speed wind turbines can be expressed as

$$
H_{\mathrm{tot}}=\left[\sum_{i=1}^{m}\left(J_{\mathrm{s}_{-} i} \omega_{\mathrm{e}^{2}}^{2} / 2 p_{\mathrm{s}_{-} i}^{2}\right)+\sum_{j=1}^{n} E_{\mathrm{w}_{-} j}\right] / S_{N}
$$

where $m$ and $n$ are the numbers of connected synchronous generators and wind turbines in the grid, respectively. $p_{\mathrm{s}_{-} i}$ and $J_{\mathrm{s}_{-} i}$ are the numbers of pole pairs and moment of inertia for synchronous generator $i$ respectively. $E_{\mathrm{w}}$ is the effective kinetic energy of the wind turbine available to the power system. $S_{\mathrm{N}}$ is the total nominal generation capacity of the power system.

As the stored kinetic energy in variable speed wind turbines cannot be automatically utilized during frequency changes as that of conventional synchronous generators (i.e., $E_{\mathrm{w}}=0$ in (1)), replacing conventional plants with large numbers of variable speed wind turbines under MPPT control can significantly reduce the effective inertia of the whole system. In addition, if newly installed wind farms are added to the power system without changing the conventional plants, $S_{\mathrm{N}}$ is increased but the total kinetic energy available to the power system remains unchanged. In this case, the effective inertia of the whole system is also reduced. This can have significant implications for power system operation and could lead to large frequency derivation. Therefore, it is important to make full use of the stored energy in the wind turbines. To better describe kinetic energy in wind turbines' rotating masses, the definition of the virtual inertia of variable speed wind turbines is given first.

The mechanical characteristics of a wind turbine generator can be expressed as

$\left\{\begin{array}{l}P_{\mathrm{m}}-P_{\mathrm{e}}=J_{\mathrm{w}} \omega_{\mathrm{r}} \frac{\mathrm{d} \omega_{\mathrm{r}}}{p_{\mathrm{w}}^{2} \mathrm{~d} t}=\frac{J_{\mathrm{w}} \omega_{\mathrm{r}} \mathrm{d} \omega_{\mathrm{r}}}{\omega_{\mathrm{s}} \mathrm{d} \omega_{\mathrm{s}}} \times \frac{\omega_{\mathrm{s}} \mathrm{d} \omega_{\mathrm{s}}}{p_{\mathrm{w}}^{2} \mathrm{~d} t}=J_{\text {vir }} \omega_{\mathrm{s}} \frac{\mathrm{d} \omega_{\mathrm{s}}}{p_{\mathrm{w}}^{2} \mathrm{~d} t} \\ J_{\mathrm{vir}}=J_{\mathrm{w}} \omega_{\mathrm{r}} \mathrm{d} \omega_{\mathrm{r}} /\left(\omega_{\mathrm{s}} \mathrm{d} \omega_{\mathrm{s}}\right)\end{array}\right.$

where $\omega_{\mathrm{r}}$ is the rotor electrical angular speed and $p_{\mathrm{w}}$ is the number of pole pairs of the wind turbine generator. $P_{\mathrm{m}}$ and $P_{\mathrm{e}}$ are the mechanical and electromagnetic power of the wind turbine, respectively. $J_{\mathrm{w}}$ is the combined natural inertia of the wind turbine system. $J_{\text {vir }}$ is defined as the virtual inertia of the wind turbine.

If the wind turbine is controlled to provide dynamic support using its kinetic energy during a frequency change, the released kinetic energy $\Delta E_{\mathrm{k}}$ can be obtained from (2) as

$$
\Delta E_{\mathrm{w}}=\int\left(P_{\mathrm{m}}-P_{\mathrm{e}}\right) \mathrm{d} t=\int\left(J_{\mathrm{vir}} \omega_{\mathrm{s}} / p_{\mathrm{w}}^{2}\right) \mathrm{d} \omega_{\mathrm{s}}
$$

If the converter controls $J_{\text {vir }}$ to be constant by adjusting the rotor speed to move away from the MPPT point, the effective kinetic energy of the wind turbine compared with a synchronous generator can be expressed as

$$
E_{\mathrm{w}}=(1 / 2) J_{\text {vir }}\left(\omega_{\mathrm{e}} / p_{\mathrm{w}}\right)^{2}
$$


According to (1) and (4), the inertia constant $H_{\text {tot }}$ of the power system with synchronous generators and wind turbines can be expressed as

$$
H_{\text {tot }}=\left[\sum_{i=1}^{m}\left(J_{\mathrm{s}_{-} i} / 2 p_{\mathrm{s}_{-} i}^{2}\right)+\sum_{j=1}^{n}\left(J_{\mathrm{vir}_{-} j} / 2 p_{\mathrm{w}_{-} j}^{2}\right) / S_{\mathrm{N}}\right] \omega_{\mathrm{e}^{2}}^{2}
$$

where $p_{\mathrm{w} j}$ and $J_{\mathrm{vir} j}$ are the numbers of pole pairs and virtual inertia for wind turbine $j$ respectively.

It can be seen from (3) that the kinetic energy of the wind turbine can be utilized for inertial response by regulating the generated power, and the equivalent inertia of the wind turbine can be described as

$$
\left\{\begin{array}{l}
J_{\mathrm{vir}}=\frac{J_{\mathrm{w}} \omega_{\mathrm{r}} \mathrm{d} \omega_{\mathrm{r}}}{\omega_{\mathrm{s}} \mathrm{d} \omega_{\mathrm{s}}} \approx \frac{\Delta \omega_{\mathrm{r}}}{\Delta \omega_{\mathrm{s}}} \cdot \frac{\omega_{\mathrm{r} 0}}{\omega_{\mathrm{e}}} J_{\mathrm{w}}=\lambda \frac{\omega_{\mathrm{r} 0}}{\omega_{\mathrm{e}}} J_{\mathrm{w}} \\
\lambda=\Delta \omega_{\mathrm{r}} / \Delta \omega_{\mathrm{s}}=\left(\omega_{\mathrm{e}} / \omega_{\mathrm{r} 0}\right) \times\left(J_{\mathrm{vir}} / J_{\mathrm{w}}\right)
\end{array}\right.
$$

where $\Delta \omega_{\mathrm{s}}$ and $\Delta \omega_{\mathrm{r}}$ are the changes of the grid and rotor angular speed during a frequency event, respectively. $\lambda$ is defined as the virtual inertia coefficient, $\omega_{\mathrm{r} 0}$ is the pre-disturbance rotor speed.

It can be observed from (6) that the virtual inertia of the wind turbine is determined not only by its natural inertia, but also by the pre-disturbance rotor speed $\omega_{\mathrm{r} 0}$ and the virtual inertia coefficient $\lambda$. Different to synchronous generators, whose rotor speeds are coupled directly to the system frequency, i.e. $\lambda=1$, the speed variation of the variable speed wind turbine can be much greater than the system frequency variation due to the asynchronous operation, i.e. $\Delta \omega_{\mathrm{r}}>\Delta \omega_{\mathrm{e}}$ and thus $\lambda>1$. Therefore, the virtual inertia of the PMSG based wind turbine can be several times of its natural inertia. However, the stored energy in the wind turbine changes with its rotor speed and is dependent on the wind velocity. Thus, the available virtual inertia also depends on the pre-disturbance rotor speed of the wind turbine.

\section{B. Supplementary derivative control}

As proved in (2) and (6), the generated power of the PMSG can be controlled according to the grid frequency derivation to emulate inertial response. The auxiliary power reference $P_{\mathrm{f}}{ }^{*}$ can be derived from (2) as

$$
P_{\mathrm{m}}-P_{\mathrm{e}}=P_{\mathrm{m}}-\left(P_{\mathrm{opt}}^{*}-P_{\mathrm{f}}^{*}\right) \approx P_{\mathrm{f}}^{*}=J_{\text {vir }}\left(\omega_{\mathrm{s}} \mathrm{d} \omega_{\mathrm{s}} / p_{\mathrm{w}}^{2} \mathrm{~d} t\right)
$$

Thus, the virtual inertia can be emulated using a supplementary control loop in addition to the normal MPPT controller.

Fig.2 shows the principles of such wind turbine inertia response for system frequency support and similar schemes have also been investigated in previous research and tested in variable speed wind turbines. However, simply combining the MPPT controller with the supplementary inertia controller can result in impaired inertia response due to their interaction during rotor speed change. For example, if grid frequency drops, the supplementary controller will try to reduce the rotor speed by increasing its active power output to release kinetic energy. However, the power reference from the MPPT controller reduces as the rotor decelerates. Thus the combined power increase for frequency support can be limited. This interaction also exists during rotor speed recovery process after primary frequency regulation, which affects the smooth recovery of the system. In addition, special attention should also be given to its impact on system power oscillations. Although larger positive gains of the derivative control can provide better inertia support to the grid, system damping is likely to be reduced leading to increased power oscillations. This will be further investigated in Section 4 and validated by experimental results in Section V.

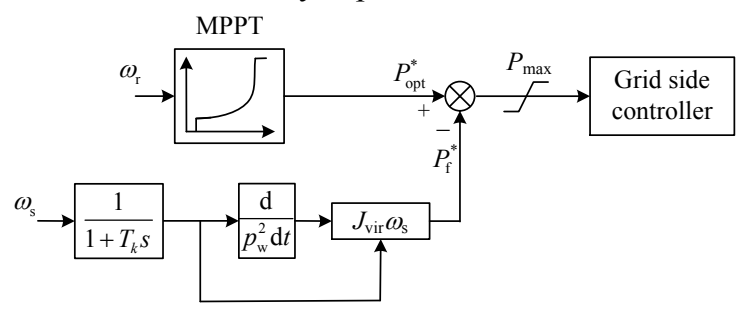

Fig. 2 Block diagram of wind turbine inertia response

\section{OPPT control for the inertial response}

In order to achieve better inertia response, the above described interaction between the supplementary inertia control and the MPPT control must be avoided. The virtual inertia control (VIC) proposed in this paper is based on the optimized power point tracking (OPPT) method. When system frequency deviation is detected, the generated power is regulated rapidly by switching the turbine operating point from the MPPT curve to the defined VIC curves. By this way, the kinetic energy in the wind turbines can be fully utilized to emulate the inertia response.

The generated power based on the conventional MPPT control can be expressed as

$$
P_{\mathrm{opt}}^{*}= \begin{cases}k_{\mathrm{opt}} \omega_{\mathrm{r}}^{3} & \left(\omega_{0}<\omega_{\mathrm{r}}<\omega_{1}\right) \\ \frac{\left(P_{\max }-k_{\mathrm{opt}} \omega_{1}^{3}\right)}{\left(\omega_{\max }-\omega_{1}\right)}\left(\omega_{\mathrm{r}}-\omega_{\max }\right)+P_{\max } & \left(\omega_{1}<\omega_{\mathrm{r}}<\omega_{\max }\right) \\ P_{\max } & \left(\omega_{\mathrm{r}}>\omega_{\max }\right)\end{cases}
$$

where $k_{\mathrm{opt}}$ is defined as the MPPT curve coefficient, $\omega_{0}$ is the cut-in angular speed. To avoid an abrupt power change around the maximum speed $\omega_{\max }$, a droop characteristic of $P-\omega$ is used for the constant speed stage, and $\omega_{1}$ is the initial angular speed in this stage. $P_{\max }$ is the maximum active power output of the PMSG.

From (8), it can be observed that different curve coefficients will generate a series of power tracking curves, defined as VIC curves. Thus, the regulation of the PMSG's operation point can be achieved by moving it from the MPPT curve with coefficient $k_{\text {opt }}$ to the VIC curve with coefficient $k_{\mathrm{VIC}}$.

The principle of the OPPT control scheme for virtual inertial response is shown in Fig.3. The wind velocity is assumed to remain constant at $8 \mathrm{~m} / \mathrm{s}$ in this example. In reality the wind speed could vary even during such a short period which could affect the inertia support capability of the wind turbine. The impact of such wind speed variation on the effectiveness of the OPPT control will be further explored in future work. In the event of a system frequency drop, the wind turbine needs decelerate to release the stored kinetic energy. Thus, the coefficient $k_{\mathrm{opt}}$ is increased and the power tracking curve is switched to the VIC curve. The operating point moves from the initial point A to B and then along the $P_{\text {VIC_max }}$ curve to C. The rotor speed at point $\mathrm{C}\left(\omega_{\mathrm{r} 1}\right)$ can be expressed using the 
frequency deviation as

$$
\omega_{\mathrm{r} 1}=\omega_{\mathrm{r} 0}+\Delta \omega_{\mathrm{r}}=\omega_{\mathrm{r} 0}+\lambda \Delta \omega_{\mathrm{s}}=\omega_{\mathrm{r} 0}+2 \pi \lambda \Delta f
$$

If the wind speed remains constant, the captured active power at point $\mathrm{A}$ can be considered to be similar to that at point $\mathrm{C}$ for small rotor speed range. Thus, the VIC curve coefficient $k_{\mathrm{VIC}}$ can be calculated as

$$
k_{\mathrm{VIC}}=\left[\omega_{\mathrm{r} 0}^{3} /\left(\omega_{\mathrm{r} 0}+2 \pi \lambda \Delta f\right)^{3}\right] k_{\mathrm{opt}}
$$

According to (10), the VIC curve coefficient $k_{\mathrm{VIC}}$ is the function of the frequency deviation, and replaces the constant coefficient $k_{\mathrm{opt}}$ of the MPPT curve. As illustrated in Fig. 3, in the event of a frequency drop, the dynamic response of the VIC can be divided into two stages: fast dynamic frequency support stage $(\mathrm{A} \rightarrow \mathrm{B} \rightarrow \mathrm{C})$ and slow rotor speed recovery stage $(\mathrm{C} \rightarrow \mathrm{A})$. Once the frequency decreases, $k_{\mathrm{VIC}}$ increases from the original value $k_{\mathrm{opt}}$ and rapidly reaches its upper limit during the first stage. According to (8) and (10), the corresponding power reference curve will then be shifted from $P_{\text {opt }}$ to $P_{\text {vic_max }}$ and the turbine's operating point is shifted from A to B with its output power changed from $P_{\mathrm{A}}$ to $P_{\mathrm{B}}$. Since the generated power is greater than the captured mechanical power, the rotor decelerates and the operating point moves along the $P_{\text {vic } \max }$ curve to the operating point C. Consequently, the kinetic energy stored in the rotating mass is released to support the grid frequency.

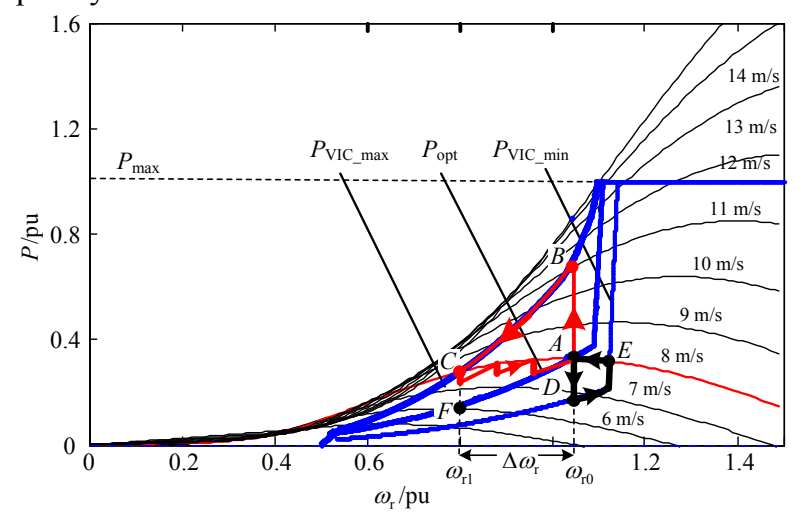

Fig.3 Scheme of the virtual inertia control based power point tracking curve

After the initial dynamic frequency response, the frequency gradually tends to stabilize with the power system's primary frequency regulation. If the power reference curve is switched from $P_{\text {vic } \max }$ to $P_{\text {opt }}$ directly, a large power step from $P_{\mathrm{C}}$ to $P_{\mathrm{F}}$ will be injected to the grid, which may result in further frequency oscillation during this recovery progress. However, using the proposed VIC method, the power reference curve will recover to MPPT curve gradually according to (10). Fig. 3 shows a special case where the recovery progress from $\mathrm{C}$ to $\mathrm{A}$ involves switching the operating point from three power reference curves. In reality, the VIC curve coefficient is continuously changed from $k_{\max }$ to $k_{\text {opt }}$ during the frequency recovery due to the continuous variation of the frequency deviation. Therefore, the rotor speed of the DFIG will smoothly recover to the initial MPPT point. In a similar way, the regulation progress during grid frequency increase can be described as the circle line of $\mathrm{A} \rightarrow \mathrm{D} \rightarrow \mathrm{E} \rightarrow \mathrm{A}$ in Fig. 3.

In order to ensure wind turbine stability at any wind velocities, the rotor speed needs to be limited within the range of $\left[\omega_{\min } \omega_{\max }\right]$, and the upper and lower limits of the VIC curves $\left(P_{\mathrm{VIC} \_ \text {max }}\right.$ and $P_{\mathrm{VIC} \_ \text {min }}$ ) can be defined accordingly. Thus the $k_{\mathrm{VIC}}$ calculated by (10) is limited within $k_{\max }$ and $k_{\min }$. The block diagram of the OPPT based virtual inertia control is shown in Fig. 4. A washout filter is used to eliminate the steady-state DC component of the frequency error.

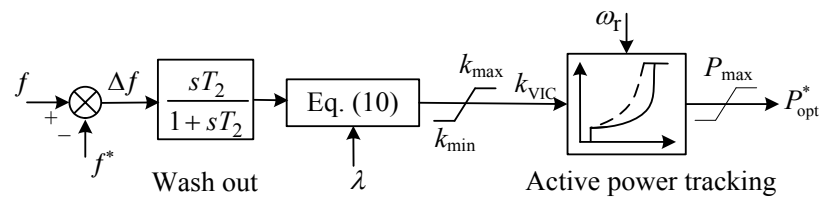

Fig.4 Structure diagram of the OPPT regulator based virtual inertia control

\section{IMPACT OF VIRTUAL INERTIA CONTROL ON POWER OSCILLATION DAMPING}

Normal variable speed wind turbines generate power in accordance with the wind speed and do not response to grid disturbance such as power oscillations. Thus, networks having high wind penetration may experience higher oscillations after disturbance due to reduced system damping. However, if the VIC regulator is implemented in the wind turbines, the fluctuation of the generated active power as the result of inertia control can also affect power oscillation which could lead to further reduction of system damping. Such potential risk on stable system operation with reduced power oscillation damping may prevent inertial control from being widely applied to wind turbines, even if an improved frequency performance can be achieved.

The equivalent circuit of a three-machine power system, as shown in Fig. 5, is used here for the theoretical evaluation of the effect on damping capability. In Fig. 5, Bus $\mathrm{B}_{2}$ is the swing bus, $V_{\mathrm{G}}$ is the wind farm grid connection point voltage, $E^{\prime}$ is the q-axis transient voltage, $V$ is the terminal voltage of $\mathrm{G}_{1}, \theta$ is the phase angle between $E^{\prime}$ and $V_{\mathrm{G}}, \delta$ is the phase angle between $E^{\prime}$ and $V$, and $\delta_{0}, \theta_{0}$ and $V_{\mathrm{G} 0}$ are the initial values of $\delta, \theta, V_{\mathrm{G}}$, respectively. $x_{1}$ and $x_{2}$ are the line reactance.

The active and reactive power of the synchronous generator $\mathrm{G}_{2}$ can be expressed as [26]

$$
\begin{gathered}
P_{\mathrm{G}}=\left(E^{\prime} V_{\mathrm{G}} / x_{1}\right) \sin \theta \\
Q_{\mathrm{G}}=\left(E^{\prime} V_{\mathrm{G}} / x_{1}\right) \cos \theta-V_{\mathrm{G}}^{2} / x_{1}
\end{gathered}
$$

The rotor motion equations of $\mathrm{G}_{2}$ can be written as

$$
\begin{gathered}
H_{\mathrm{G}}\left(\mathrm{d} \omega_{\mathrm{s}} / \mathrm{d} t\right)=P_{\mathrm{Gm}}-P_{\mathrm{G}}-D\left(\omega_{\mathrm{s}}-\omega_{\mathrm{e}}\right) \\
\mathrm{d} \delta / \mathrm{d} t=\omega_{\mathrm{s}}-\omega_{\mathrm{e}}
\end{gathered}
$$

where $H_{\mathrm{G}}, P_{\mathrm{Gm}}, P_{\mathrm{G}}$ and $\omega_{\mathrm{s}}$ are the inertia constant, electromagnetic power, mechanical power and angular velocity of $\mathrm{G}_{2}$, respectively. $D$ is the damping coefficient.

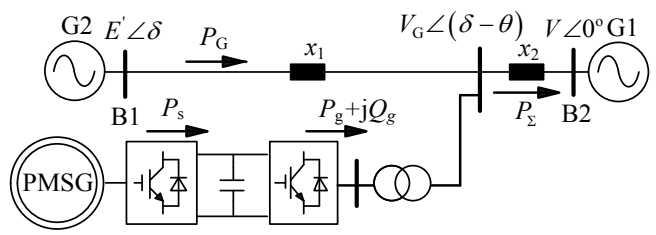

Fig. 5 Equivalent circuit of the power system with wind farms

Assuming that mechanical power $P_{\mathrm{Gm}}$ remains constant 
throughout the transient process, the rotor motion equations developed by the small perturbation method can be expressed as

$$
H_{\mathrm{G}} p^{2} \Delta \delta+D p \Delta \delta+\Delta P_{\mathrm{G}}=0
$$

where $\Delta P_{\mathrm{G}}$ is the active power variation of $\mathrm{G}_{2}, p$ is the differential divisor.

In a linear system, the impact of the active power regulation and the grid voltage variation for the system damping can be described by a set of linear ordinary equations, which can be solved respectively. Hence, the connection point voltage $V_{\mathrm{G}}$ can be regarded as a constant in the analysis of the active power regulation for system damping. Thus, the small perturbation quantity of $P_{\mathrm{G}}$ can be obtained as

$$
\Delta P_{\mathrm{G}}=\left(E^{\prime} V_{\mathrm{G}} / x_{1}\right) \cos \theta_{0} \Delta \theta
$$

\section{A. Supplementary derivative control on power oscillation damping}

As the auxiliary power reference $P_{\mathrm{f}}$ generated by the supplementary inertial controller fluctuates with the grid power/frequency oscillations, the system damping capability will be changed.

As shown in Fig. 5, the network power equation is given by

$$
P_{\Sigma}=P_{\mathrm{G}}+P_{\mathrm{g}}
$$

where $P_{\Sigma}=\left(V_{\mathrm{G}} V / x_{2}\right) \sin (\delta-\theta)$. Applying small perturbation, the following equation can be derived from (17)

$$
\left[V_{\mathrm{G}} V \cos \left(\delta_{0}-\theta_{0}\right) / x_{2}\right] \times(\Delta \delta-\Delta \theta)=\Delta P_{\mathrm{G}}+\Delta P_{\mathrm{g}}
$$

Neglecting the small rotor speed variation in the analysis and according to (14), the small perturbation quantity of $P_{\mathrm{f}}$ can be obtained as

$$
\Delta P_{\mathrm{f}}=-H_{\mathrm{vir}}\left(\mathrm{d} \Delta \omega_{\mathrm{s}} / \mathrm{d} t\right)=-H_{\mathrm{vir}} p^{2} \Delta \delta=\Delta P_{\mathrm{g}}
$$

The above equation describes the additional power generated by the supplementary controller. Substituting (19) and (16) into (18), $\Delta \theta$ is obtained as

$$
\Delta \theta=a_{0} \Delta \delta+\left[H_{\mathrm{vir}} a_{0} x_{2} /\left(V_{\mathrm{G}} V \cos \left(\delta_{0}-\theta_{0}\right)\right)\right] p^{2} \Delta \delta
$$

Then, substituting (20) and (16) into (15), the linear differential equations of the rotor motion can be express as

$$
\begin{gathered}
{\left[H_{\mathrm{G}}+H_{\mathrm{vir}} E^{\prime} a_{0} x_{2} \cos \theta_{0} /\left(V \cos \left(\delta_{0}-\theta_{0}\right) x_{1}\right)\right] p^{2} \Delta \delta} \\
+D p \Delta \delta+\left(a_{0} E^{\prime} V_{\mathrm{G}} / x_{1}\right) \cos \theta_{0} \Delta \delta=0
\end{gathered}
$$

Equation (21) indicates that the eigenvalues move toward the right half plane for increased inertia indicating a reduced damping from the supplementary derivative control.

\section{B. OPPT control}

For the proposed OPPT control, according to (10), the output power of the PMSG can be expressed as

$$
P_{\mathrm{g}}=\left[k_{\mathrm{opt}} \omega_{\mathrm{r} 0}^{3} /\left(\omega_{\mathrm{r} 0}+\lambda\left(\omega_{\mathrm{s}}-\omega_{\mathrm{e}}\right)\right)^{3}\right] \omega_{\mathrm{r}}^{3}
$$

During power oscillations, the regulation of $P_{\mathrm{g}}$ mainly depends on the variation of coefficient $k_{\mathrm{VIC}}$. Neglecting the small rotor speed variation, the small perturbation quantity of $P_{\mathrm{g}}$ can be obtained as

$$
\Delta P_{\mathrm{g}} \approx-\frac{3 \lambda k_{\mathrm{opt}} \omega_{\mathrm{r} 0}^{6}}{\left[\omega_{\mathrm{r} 0}+\lambda\left(\omega_{\mathrm{s} 0}-\omega_{\mathrm{e}}\right)\right]^{4}} \Delta \omega_{\mathrm{s}} \approx-3 \lambda k_{\mathrm{opt}} \omega_{\mathrm{r} 0}^{2} \Delta \omega_{\mathrm{s}}
$$

Substituting (16) and (23) into (18), $\Delta \theta$ is obtained as

$\Delta \theta=a_{0} \Delta \delta+\left[3 \lambda k_{\mathrm{opt}} \omega_{\mathrm{r} 0}^{2} a_{0} x_{2} /\left(V_{\mathrm{G}} V \cos \left(\delta_{0}-\theta_{0}\right)\right)\right] p \Delta \delta$

where $a_{0}=x_{1} V \cos \left(\delta_{0}-\theta_{0}\right) /\left(x_{2} E^{\prime} \cos \theta_{0}+x_{1} V \cos \left(\delta_{0}-\theta_{0}\right)\right)$.

Thus the linear differential equations of the rotor motion can be obtained by substituting (24) and (16) into (15) as

$H_{\mathrm{G}} p^{2} \Delta \delta+\left(D+D_{\mathrm{P}}\right) p \Delta \delta+\left(a_{0} E^{\prime} V_{\mathrm{G}} / x_{1}\right) \cos \theta_{0} \Delta \delta=0$

where $D_{\mathrm{P}}=3 \lambda k_{\mathrm{opt}} \omega_{\mathrm{r} 0}^{2} a_{0} x_{2} E^{\prime} \cos \theta_{0} /\left(x_{1} V \cos \left(\delta_{0}-\theta_{0}\right)\right)>0$.

According to (25), the system damping is increased from $D$ to $D+D_{\mathrm{p}}$, by the wind turbine's fast power regulation. This indicates that the OPPT controller can also provide power oscillation damping to the connected network.

As can be seen from above analysis and design, compared with the conventional supplementary derivative control which results in reduced system damping, the OPPT control method proposed in this paper can realize both inertia response and improved power oscillation damping.

\section{EXPERIMENTAL RESULTS}

Experimental tests on laboratory prototypes have been carried out to verify the theoretical analysis. The experimental platform is shown in Fig.6 and consists of two synchronous generators $\left(\mathrm{G}_{1}, \mathrm{G}_{2}\right)$, a PMSG-based wind turbine with the mechanical turbine and drive chain emulated using a controlled machine set, and three aggregated loads $\left(\mathrm{L}_{1}, \mathrm{~L}_{2}\right.$ and $\left.\mathrm{L}_{3}\right) . \mathrm{G}_{1}$ and $\mathrm{G}_{2}$ are rated at $15 \mathrm{kVA}$ and $6.8 \mathrm{kVA}$, respectively. The wind turbine is rated at $10 \mathrm{kVA}$ which gives a wind power penetration level of around $31 \%$ for the tested system. The three loads $L_{1}$, $\mathrm{L}_{2}$ and $\mathrm{L}_{3}$ can be varied during tests and their maximum ratings are $10 \mathrm{~kW}, 4 \mathrm{~kW}$ and $4 \mathrm{~kW}$, respectively. The $\mathrm{AC}$ common coupling voltage in the experimental system is $500 \mathrm{~V}$. Real-time control of the wind turbine was accomplished using a TMS320F28335 board, whereas the data acquisition was implemented using DL850, cRIO-9025 controller and NI data acquisition cards. The sampling time of the control system is $50 \mu$ s and the PWM frequency for the PMSG converters is 10 $\mathrm{kHz}$. In the experiments, $\mathrm{G}_{1}$ regulates frequency by its governor with $4 \%$ droop setting whereas $\mathrm{G}_{2}$ operates at constant active power mode and does not participate in frequency regulation. Although the test hardware in the laboratory may have different characteristics compared to real power plants, the obtained experimental results should give good indications of the effectiveness of the proposed method and provide useful guidance for real system design. 


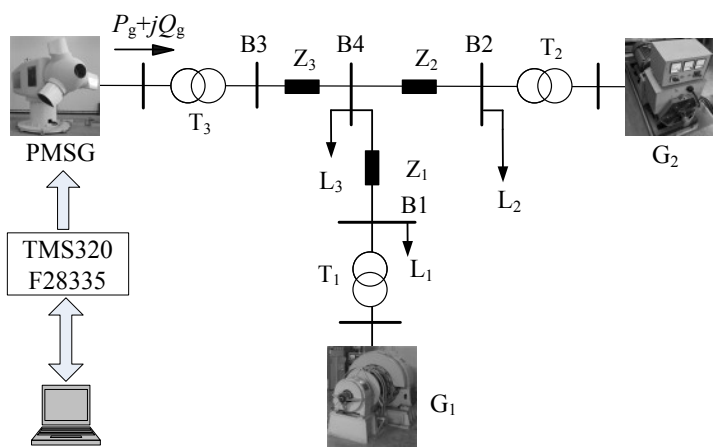

(a)

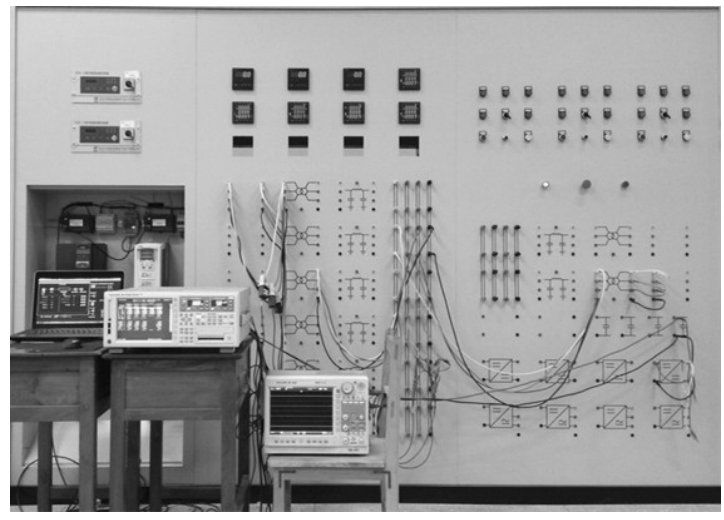

(b)

Fig.6 Experimental system: (a) schematic diagram, (b) circuit patch board.

\section{A. Inertial responses under sudden load change}

The impact of different virtual inertia coefficients in (10) on the wind turbine inertia response and system frequency is tested first, and the results are shown in Fig. 7. The wind velocity was set as $8 \mathrm{~m} / \mathrm{s}$ by the motor-based emulator and the PMSG-based turbine initially operated at the maximum power point. During the test, Load $\mathrm{L}_{1}$ was increased from $5.2 \mathrm{~kW}$ to $6.2 \mathrm{~kW}$ causing a temporary fall of the system frequency.

In Figs. 7 (a)-(c), the dynamic responses of the network frequency, the PMSG' active power $P_{\mathrm{g}}, \mathrm{G}_{1}$ 's active power output $P_{\mathrm{G} 1}$ and $\mathrm{G}_{2}$ 's active power output $P_{\mathrm{G} 2}$ are compared for different control methods and different virtual inertia coefficients $\lambda$. Without the proposed VIC scheme shown in Fig. $7(\mathrm{a})$, the active power of the wind turbine remains almost constant at $1.7 \mathrm{~kW}$. A large frequency drop of $0.55 \mathrm{~Hz}$ can be observed due to the small system inertia. For the OPPT control scheme, the virtual inertia responses of the PMSG can be regulated by adopting different values of the virtual inertia coefficient $\lambda$. The wind turbine switches the control mode from the MPPT control to the VIC control when the frequency deviation occurs. For the results shown in Fig. 7 (b) with $\lambda=1$, the active power of the wind turbine is increased by $0.25 \mathrm{~kW}$ and a reduced frequency drop of $0.45 \mathrm{~Hz}$ is observed compared to system without VIC. To further increase the virtual inertia of the wind turbine, $\lambda=9$ is used and the results are shown in Fig. 7 (c). It can be seen from Fig. 7 (c) that the wind turbine output active power is increased by $0.63 \mathrm{~kW}$ which results in a much smaller frequency drop of $0.21 \mathrm{~Hz}$. This represents $61.8 \%$ reduction in frequency deviation compared to system without VIC shown in Fig. 7 (a). With $\mathrm{G}_{1}$ 's primary frequency regulation, the frequency deviation gradually reduces and the system frequency recovers to its normal value after 16s. During the recovery progress, the output power of the PMSG decreases slowly to avoid unnecessary disturbances and provides a smooth recovery even with the large $\lambda$ of 9 .
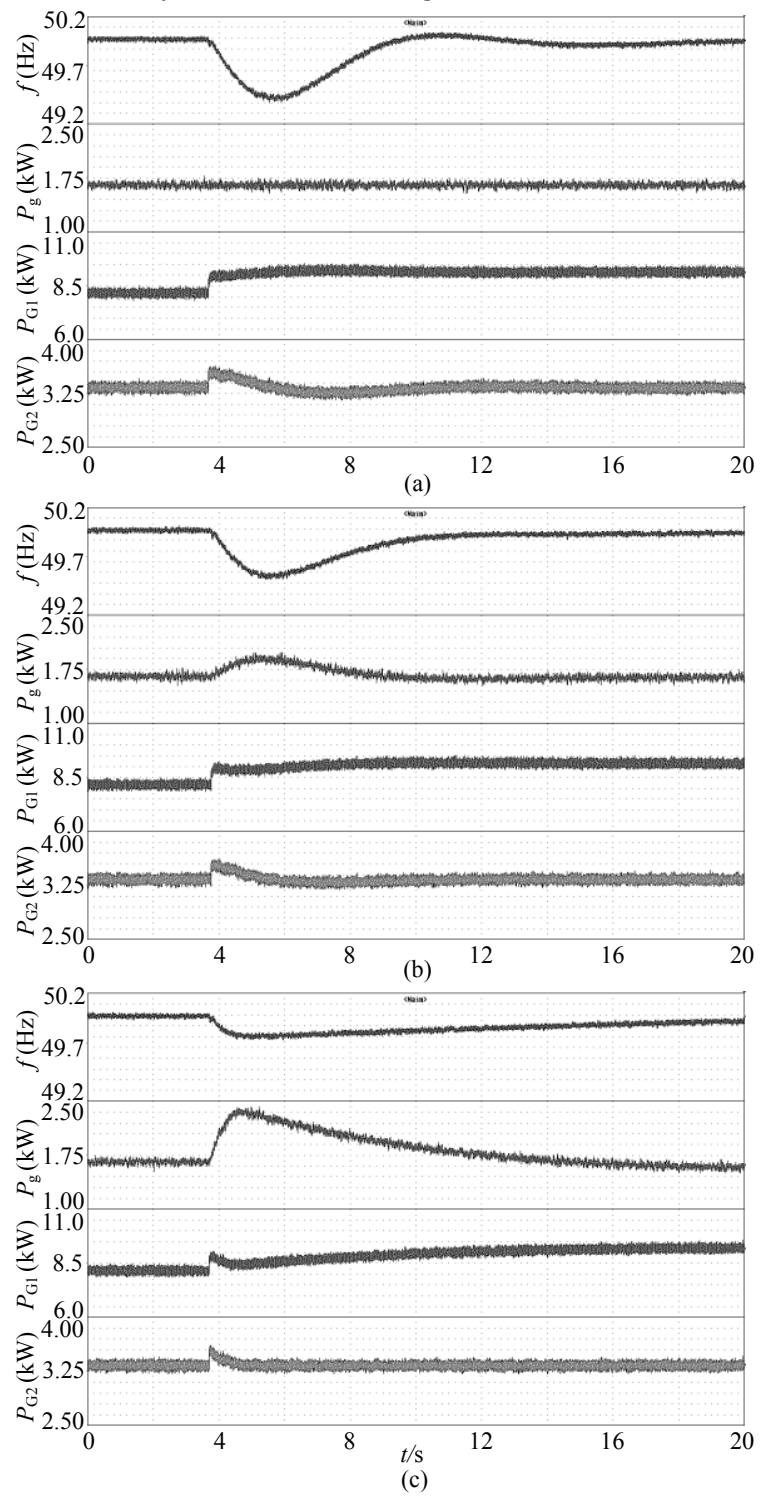

Fig.7 Dynamic responses of the network during load $\mathrm{L}_{1}$ sudden increase $1 \mathrm{~kW}$. (a) without VIC. (b) VIC $(\lambda=1)$. (c) VIC $(\lambda=9)$.

As evident from the analysis and test results, greater virtual inertia (i.e., higher $\lambda$ ) helps to reduce the rate of change of frequency. However, it is observed that as $\lambda$ increases, the frequency recovery rate becomes slightly slower. This is due to the slower power increase from $\mathrm{G}_{1}$ since frequency derivation now is smaller as the result of increased inertia support from the wind turbine.

\section{B. Comparison with supplementary derivative control during load increase}

To further illustrate the advantages of the proposed VIC scheme on inertia support and system damping, experimental results are compared for the three cases, i.e. Case A: without inertia control; Case B: with the supplementary derivative control; and Case C: with the proposed OPPT control. During the tests, $\mathrm{L}_{1}$ was increased from $5.2 \mathrm{~kW}$ to $6.2 \mathrm{~kW}$ and the results for the three cases are shown in Fig. 8 (a)-(c), respectively. 

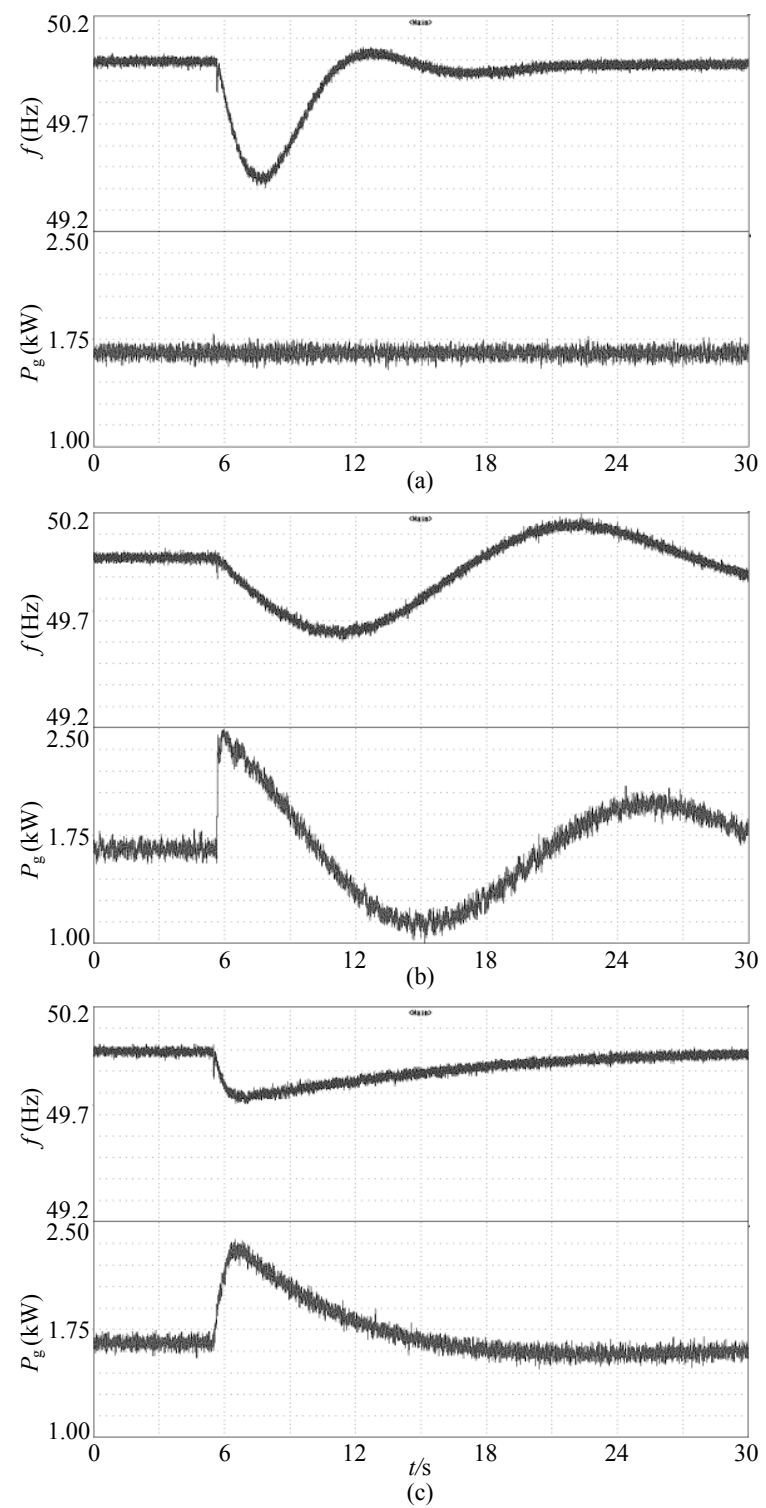

Fig.8 Comparisons of the inertia response during sudden load increase. (a) Case A, (b) Case B, (c) Case C

As shown in Fig. 8, compared to Case A, the frequency nadir and the change rate are reduced when inertia control is applied in Case B and Case C. Furthermore, Case C with the proposed VIC has the smallest frequency drop and smoothest recovery. This can be explained by observing the wind turbine power outputs between the proposed OPPT controller and the supplementary controller. As shown, the output power of the wind turbine with the supplementary inertia control shown in Fig. 8 (b) only provides frequency support for the initial $5 \mathrm{~s}$, while the duration of the more effective power support in Case $\mathrm{C}$ is about $10 \mathrm{~s}$. In contrast to Case B where significant oscillations are observed during recovery, Case $\mathrm{C}$ provides a stable and smooth recovery after inertia support. . In fact, the impaired power response in Case B is mainly caused by the variation of $P_{\mathrm{opt}}{ }^{*}$ of the MPPT controller.

C. Comparison with supplementary derivative control on power oscillation damping after short circuit fault

In order to compare the effects of the OPPT control and the supplementary derivative control on power system oscillation damping, a $0.1 \mathrm{~s}$ three-phase short circuit fault at bus $\mathrm{B}_{2}$ was applied. The initial wind speed was $8 \mathrm{~m} / \mathrm{s}$ and $\lambda$ was set to an intermediate value of 7. In Fig. 9, the AC voltage, the DC-link voltage of the PMSG's converters, the wind turbines' active power, and the active power of $\mathrm{G}_{1}$ are compared under the three same cases illustrated in the previous section. The severity of the three-phase short circuit fault can be seen from the AC voltage waveforms shown in Fig. 9(a).
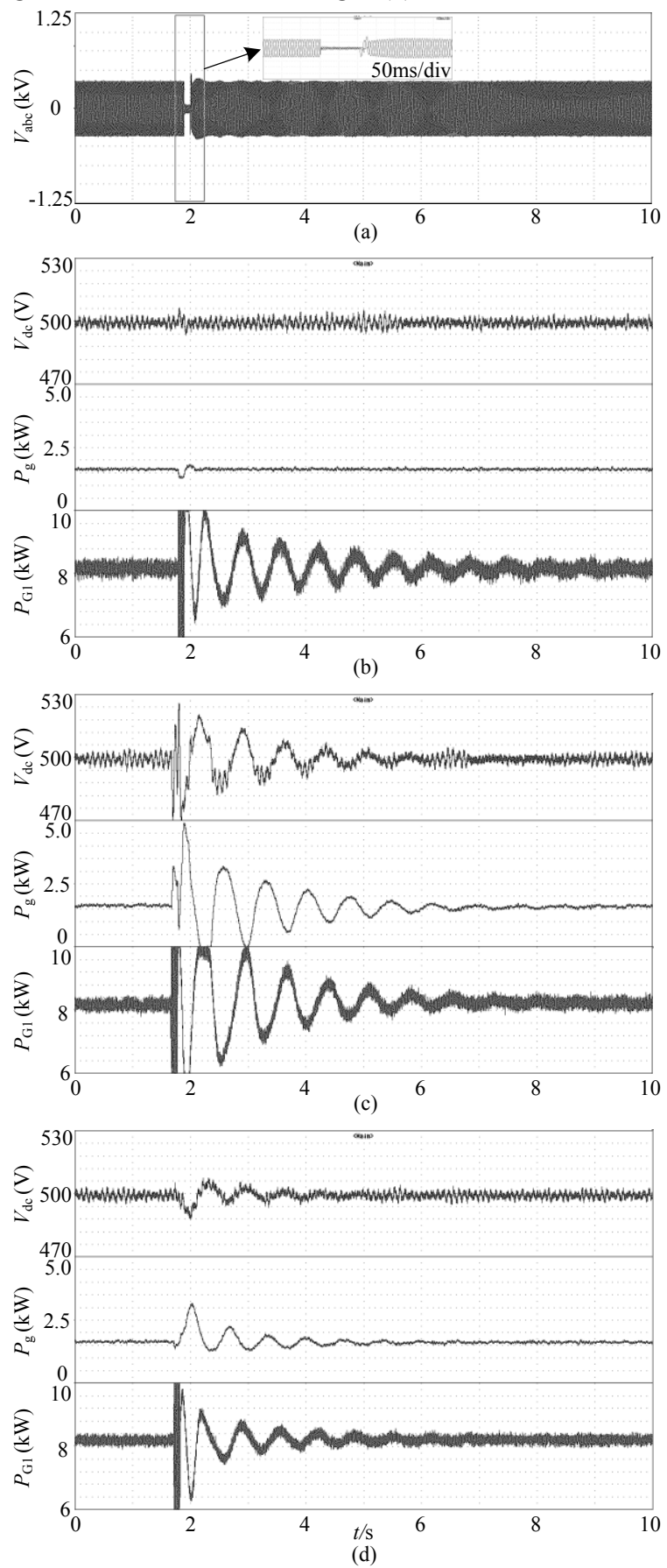

Fig. 9 Dynamic responses of the network after short circuit fault. (a) AC voltage; (b) Case A; (c) Case B; (d) Case C.

For case A shown in Fig. 9(b), when the short circuit fault happens, the grid side converter goes into current limit and its active power export to the grid is reduced. Since the generator side converter controls the DC-link voltage, it automatically 
reduces power output from the PMSG and consequently the DC-link voltage remains stable with only less than $5 \%$ increase. During the fault period, the surplus mechanical power in the wind turbine is stored as kinetic energy in the wind turbines' rotating masses. However, the power oscillation in this weak network cannot be damped effectively, since the wind turbine makes no contribution to system damping under this basic control scheme.

As shown in Fig. 9 (c) for Case B, the fast active power response from the wind turbine to the network frequency variation is generated by the supplementary derivative controller. Due to the adverse effect of this control resulting in reduced system damping, the system oscillates for a prolonged period after fault clearance. Compared to Case A, the increased DC-link voltage and power oscillations can seriously affect the wind turbine operation and grid stability.

In Fig.9 (d), with the OPPT control, power oscillations in $\mathrm{G}_{1}$ are significantly reduced. Compared to Case A, the amplitude of $\mathrm{G}_{1}$ 's power oscillation is much lower and its duration is reduced from around $6 \mathrm{~s}$ to $3 \mathrm{~s}$. This proves that the active power fluctuation of the wind turbines generated by the proposed controller helps damp the power oscillation. The DC-link voltage is also well maintained. Therefore, Case $\mathrm{C}$ achieves the best power oscillation damping performance among the three cases.

\section{Comparison with supplementary derivative control after short circuit fault and load increase}

System operation during a $0.1 \mathrm{~s}$ three-phase short circuit fault at bus $\mathrm{B} 2$ immediately followed by $1 \mathrm{~kW}$ load increase is tested to further illustrate the performance of the proposed OPPT control. The experimental results for the three cases are shown in Fig. 10.

Under such test conditions, the initial frequency change and power oscillations are generated by the short circuit fault. The system frequency then decreases due to load increase. The dynamic response of the network frequency with supplementary derivative control is better than that with no inertia control as evident from Figs. 10 (a) and (b). However, the power oscillations are not effectively suppressed in Case B due to the lack of system damping. Again the proposed OPPT control has the best performance of frequency support and power oscillation damping among the three cases. This is due to the fact that the proposed OPPT control provides simultaneous inertia response and system damping. Thus, the controller can provide additional benefit for dynamic stability of power systems and is well suited for wind power applications.
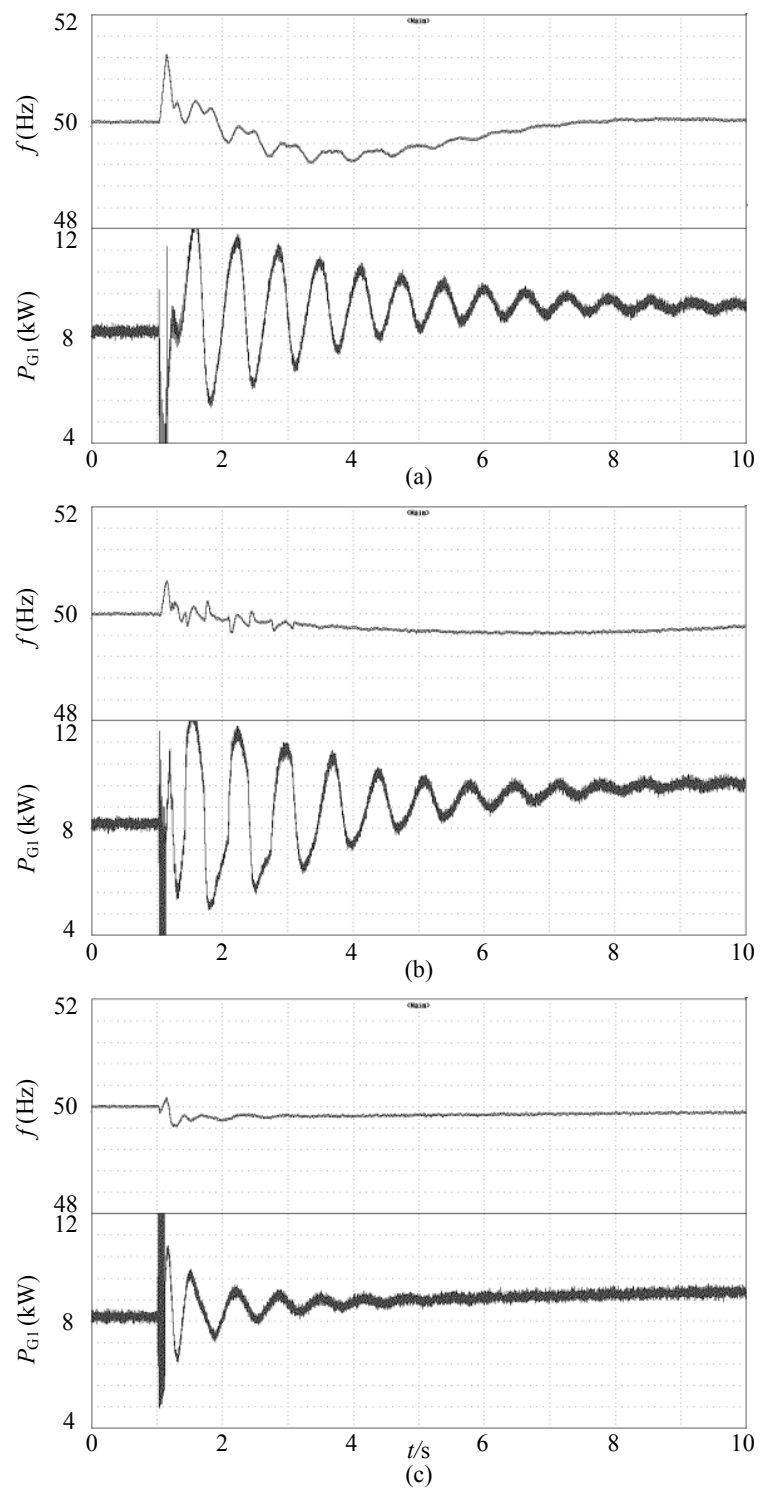

Fig.10 Dynamic responses of the system after short circuit fault and load increase. (a) Case A, (b) Case B, (c) Case C.

\section{CONCLUSION}

This paper investigates power regulation of PMSG-based wind turbines during transient events for enhancing the grid inertial response and damping capability. Virtual inertia control (VIC) based on optimized power point tracking (OPPT) for PMSG-based wind turbine is proposed to provide inertial response and power oscillation damping. The main conclusions drawn from the proposed control method are as follows.

1) $\mathrm{AC}$ networks with high wind power penetration are likely to have reduced effective inertia and damping capability. Thus, wind turbines equipped with virtual inertia and oscillation damping functions become increasingly necessary for ensuring system stability.

2) Compared with the supplementary derivative control, the proposed OPPT control scheme avoids negative interactions between inertia response and the MPPT control. The OPPT method can change the emulated inertia of the wind turbines by adjusting the virtual inertia coefficient. Furthermore, a smoother recovery of the rotor 
speed back to the optimal value is also achieved after inertia support.

3) Different from the supplementary derivative control, OPPT control can also contribute system damping. Thus, the proposed OPPT control scheme for wind turbines has both inertial response and positive damping function, providing an enhanced active power support for improved system stability.

\section{REFERENCES}

[1] N. Miller and P. E. Marken, "Facts on grid friendly wind plants," in Proc. IEEE Power and Energy Society General Meeting, 2010, pp. 1-7.

[2] M. Cardinal and N. Miller, "Grid friendly wind plant controls: Wind control-Field Test Results," in American Wind Energy Conference, 2006, pp. $1-8$.

[3] J. Morren, S. de Haan, W. Kling, and J. Ferreira, "Wind turbines emulating inertia and supporting primary frequency control," IEEE Trans. Power Syst., vol. 21, no. 1, pp. 433-434, Feb. 2006.

[4] J. Ekanayake and N. Jenkins, "Comparison of the response of doubly fed and fixed-speed induction generator wind turbines to changes in network frequency," IEEE Trans. Energy Convers., vol. 19, no. 4, pp. 800-802, Dec. 2004.

[5] L. Holdsworth, J. B. Ekanayake, and N. Jenkins, "Power system frequency response from fixed speed and doubly fed induction generator-based wind turbines," Wind Energy, vol. 7, no. 1, pp. 21-35, Mar. 2004.

[6] A. Mullane and M. O'Malley, "The inertial response of induction-machine-based wind turbines," IEEE Trans. Power Syst., vol. 20, no. 3, pp. 1496-1503, Aug. 2005.

[7] J. G. Slootweg and W. L. Kling, "The impact of large scale wind power generation on power system oscillations," Electric Power Systems Research, vol. 67, no. 1, pp. 9-20, Feb. 2011.

[8] G. Tsourakis, B. M. Nomikos, and C. D. Vournas, "Contribution of doubly fed wind generators to oscillation damping," IEEE Trans. Energy Convers., vol. 24, no. 3, pp. 783-791, Sep. 2009.

[9] Z. S. Zhang, Y. Z. Sun, and J. Lin, "Coordinated frequency regulation by doubly fed induction generator-based wind power plants," IET Renew. Power Gener., vol. 6, no. 1, pp. 38-47, Jan. 2012.

[10] G. Ramtharan, J. B. Ekanayake, and N. Jenkins, "Frequency support from doubly fed induction generator wind turbines," IET Renew. Power Gener., vol. 1, no. 1, pp. 3-9, Mar. 2007.

[11] J. M. Mauricio, A. Marano, A. G. Expósito, and J. L. M. Ramos, "Frequency regulation contribution through variable-speed wind energy conversion systems," IEEE Trans. Power Syst., vol. 24, no. 1, pp. 173-180, Feb. 2009.

[12] D. Gautam, L. Goel, R. Ayyanar, V. Vittal, and T. Harbour, "Control strategy to mitigate the impact of reduced inertia due to doubly fed induction generators on large power systems," IEEE Trans.Power Syst., vol. 26, no. 1, pp. 214-224, Feb. 2011.

[13] G. Lalor, A. Mullane, and M. O'Malley, "Frequency control and wind turbine technologies," IEEE Trans. Power Syst., vol. 20, no. 4, pp.1905-1913, Nov. 2005.

[14] J. M. Mauricio, A. Mano, A. G. Expósito, and J. L. M. Ramos,, "Frequency regulation contribution through variable-speed wind energy conversion systems," IEEE Trans. Power Systs., vol. 24, no. 1, pp. 173-180, Feb. 2009

[15] L. R. C. Chien, W. T. Lin, and Y. C. Yin, "Enhancing frequency response control by DFIGs in the high wind penetrated power systems," IEEE Trans. Power systs., vol. 26, no. 2, pp. 710-718, May 2011.

[16] G. Rogério, D. Almeida, and J. A. Peças Lopes, "Participation of doubly fed induction wind generators in system frequency regulation," IEEE Trans.Power Syst., vol. 22, no. 3, pp. 944-950, Aug. 2007.

[17] Z. X. Miao, L. L. Fan, D. Osborn, and S. Yuvarajan," "Control of DFIG-based wind generation to improve interarea oscillation damping," IEEE Trans. Energy Convers., vol. 24, no. 2, pp. 415-422, Jun. 2009.

[18] F. M. Hughes, O. A. Lara, N. Jenkins, and G. Strbac, "A power system stabilizer for DFIG-based wind generation," IEEE Trans. Power Syst., vol. 21, no. 2, pp. 763-772, May 2006.

[19] D. Gautam, V. Vittal, R. Ayyanar, and T. Harbour, "Supplementary control for damping power oscillations due to increased penetration of doubly fed induction generators in large power systems," in Proc. IEEE Power Systs. Conference and Exposition, 2011, pp. 1-6.

[20] L. L. Fan, H. P. Yin, and Z. X. Miao, "On active/reactive power modulation of DFIG-based wind generation for interarea oscillation damping," IEEE Trans. Energy Convers., vol. 26, no. 2, pp. 513-521, Jun. 2011.

[21] S. Li, T. A. Haskew, and L. Xu, "Conventional and novel control designs for direct driven PMSG wind turbines," Electric Power Syst. Res., vol. 80, no. 3, pp. 328-338, Mar. 2010.

[22] J. F. Conroy and R. Watson, "Frequency response capability of full converter wind turbine generators in comparison to conventional generation," IEEE Trans.Power Syst., vol. 23, no. 2, pp. 649-656, May 2008.

[23] H. Geng, D. Xu, B. Wu, and G. Yang, "Comparison of oscillation damping capability in three power control strategies for PMSG-based WECS," Wind Energy, vol. 14, pp. 389-406, Mar. 2011.

[24] H. Geng, G. Yang, D. W. Xu, and B. Wu, "Unified power control for PMSG-based WECS operating under different grid conditions," IEEE Trans. Energy Convers., vol. 26, no. 3, pp. 822-830, Sep. 2011.

[25] A. D. Hansen, F. Lov, and P. Sorensen, et al. "Dynamic wind turbine models in power system simulation tool digsilent," Risø National Laboratory, Roskilde, Denmark, pp. 117, Aug. 2007.

[26] P. Kundur, Power systems stability and control. NewYork: McGraw-Hill, 1994. 